\title{
Application of modern Enterprise Resource Planning (ERP) systems in the era of digital transformation
}

\author{
Teodora Ivanović \\ University of Novi Sad, Faculty of Economics in Subotica, Subotica, Serbia \\ Mirjana Marić \\ University of Novi Sad, Faculty of Economics in Subotica, Subotica, Serbia
}

\begin{abstract}
Modern digital technologies - acronym SMACIT (Social, Mobile, Analytics, Cloud, and Internet of Things [loT]) - are the generator of digital business transformation today. Companies that have done their business in the same way for years can not, without adequate transformation, respond to the fresh challenges induced by modern digital technologies. The authors described the concept and content of digital business transformation and the impact of modern digital technologies on ERP systems. The paper conducts empirical research using the survey method. We conducted a survey on a sample of 25 small companies in Serbia. The results of the empirical research show modern ERP systems in small companies in Serbia, and the main drivers and barriers for their application.
\end{abstract}

Keywords

Digital transformation, digital technologies, ERP system, Cloud ERP system

\section{Introduction}

Modern digital technologies - acronym SMACIT (Social, Mobile, Analytics, Cloud, and Internet of Things [IoT] - are the generator of digital business transformation today. Companies have been doing their business in the same way for years, while, according to Wade (2015), with various digital technologies, they are facing the inevitable digital transformation of their business. Wade highlights seven categories of content that can be digitally transformed in a company: business model (how the organization earns), organizational structure, people, processes, IT capacities (how information is managed), offer (what products and services the organization offers), and engagement model (how the organization deals with its clients and other actors). These categories are the most important elements of the organizational value chain related to digital transformation (Wade, 2015).
Organizations in all branches of industry feel the pressure to digitize and know that they have to do it quickly before falling behind innovative and digitally focused competitors or brand new market players. (Leipzig, Gamp, Manz, \& Schöttle, 2017)

An integrated information system is a complete software solution that meets the overall business model of the company, supports and integrates all its organizational parts and business functions, and connects them into business processes within the organization and business processes that connect the company with business partners. An integrated information system is a prerequisite for the success of modern companies that operate based on electronic business models, and which are characterized by digital technologies. The integrated information system supports business processes internally within the organization and business processes externally towards business partners. The most important integrated software 
solution on which modern companies should base their more effective business is ERP. The application of the ERP system ensures the integrity of information and a unique database available to employees in any organizational part of the company. The integrity, timeliness, and quality of business data is a necessary prerequisite for making adequate and timely decisions and ensuring competitiveness in the modern market.

The application of ERP systems requires the company to improve its business processes. This includes a thorough analysis of existing processes and their partial or radical redesign to determine the best way to implement them and achieve significant improvements in process performance measures. These include cost, quality, and speed. Redesign of business processes, and changes in entire business models are even more necessary in the conditions of developing ERP systems under the influence of modern digital technologies.

The era of digital transformation enables small companies to use modern ERP systems, such as the Cloud ERP system and mobile ERP system, although their use has reduced the cost of maintaining servers and other necessary hardware and software infrastructure (Picek, Mijac, \& Androcec, 2017).

Based on the described subject of research, the authors of the paper asked the following research questions:

RQ1: What is the application of modern ERP systems in small companies in Serbia in the era of digital transformation?

RQ2: What are the drivers and barriers to the application of modern ERP systems in small companies in Serbia?

We will describe the answers to these questions in the chapter Results of empirical research. The results of the conducted empirical research show modern ERP systems in small companies in Serbia, and the main drivers and barriers for their application.

\section{Methodology}

Theoretical research included the analysis of reference literature from the described domain of the research subject and was the basis for starting empirical research.

Empirical research was conducted with a survey method, using a questionnaire as an instrument for its implementation. To facilitate distribution, the questionnaire was created in electronic form, on Google Drive, using the Google Forms tool. The initial version of the questionnaire was made at the end of January 2020, after which it was sent to three experts for evaluation. The experts assessed the significance of each potential issue and provided accompanying comments and suggestions for several issues. Questions with a content validity index $<0.8$ were eliminated from the questionnaire, and several questions were reformulated, because of the evaluator's suggestions that they were not clear enough. The index of content validity (Polit \& Beck, 2006) of the questionnaire was 0.83 . The revised questionnaire was sent to the experts for reevaluation; however, there were no requests for additional changes. The questionnaire contained nine questions. The research was conducted on a sample of 25 small companies in Serbia, of different activities. The criteria for small companies in Serbia are that they have less than 50 employees, that their gross income is up to 2.5 million euros and the value of the asset is 1 million euros. For a company to fall into this category, it is enough to meet two of the three conditions.

The research was realized through 3 phases. In the first phase, the Business Registers Agency was consulted to define a preliminary list of small companies for potential participation in the research. The companies were contacted by phone, but only 25 accepted to participate. In the second phase, e-questionnaires were sent to the companies that agreed to take part in the research. In the third phase of the research, the collected data was processed.

\section{The era of digital transformation}

Digitization is part of the great global trend of the fourth industrial revolution (Industrie 4.0), which provides companies with glorious opportunities for business transformation, but carries the risk of their survival if the transformation is not effective.

For this reason, organizations in all branches of industry feel the pressure to digitalize before falling behind innovative and digitally oriented competitors or unknown market players (Leipzig et al., 2017). The potential benefits of digitization are multiple, including: increasing sales, improving productivity, fostering innovation in value creation, and creating fresh forms of customer interaction (Matt, Hess, \& Benlian, 2015).

The term digital transformation encompasses all transformational effects because of the application of new SMACIT) technologies in business. Digital transformation involves the use of modern technology in order to radically improve the performance or achievements of the company. 
The exploitation and integration of digital technologies can influence the transformation of many parts of a company, starting with the products themselves, sales channels, and the entire supply chain. Often, entire business models can be redesigned or replaced (Matt et al., 2015).

Digital business transformation is a significant challenge and can be efficient and effective only if the company has a clear picture and goal of why it would transform. Several internal and external factors can motivate the digital transformation of business. Sometimes, the motive may be customers who are looking for improved service, lower prices, and a higher level of quality. The motive for transformation may also stem from the competition that has a better offer, a better business model, or lower prices. A powerful motive for change also comes from modern digital technologies that provide new opportunities. Digital technologies can provide a company with competitive differentiation if it is first adopted or integrated into new ways (Wade, 2015).

The complexity of digital transformation are far greater than the previous transformations that originated from information technologies. Although companies recognize its importance, it is still a significant challenge for most companies to start it, and especially to reach a position in which they can exploit its benefits. The authors suggest that only a few companies develop the right management and technology skills to exploit the transformational benefits of new digital technologies (Hess, Benlian, Matt, \& Wiesböck, 2016).

Thus, the digital transformation of a business can take many forms, so it is necessary for a company to explicitly determine the priorities of its transformation. Wade (2015) identified seven categories of content that can be digitally transformed in a company: business model (how the organization earns), organizational structure, people, processes, IT capacities (how to manage information), offer (which produce and services the organization offers) and the engagement model (how the organization deals with its clients and other actors) (Wade, 2015).
Table 1 Transformation categories

\begin{tabular}{|c|c|}
\hline $\begin{array}{l}\text { Transformation } \\
\text { category }\end{array}$ & $\begin{array}{l}\text { Orientation questions for each of the } \\
\text { transformation categories of the } \\
\text { organization }\end{array}$ \\
\hline \multirow{4}{*}{$\begin{array}{l}\text { Business model } \\
\text { (how to make } \\
\text { money) }\end{array}$} & $\begin{array}{l}\text { What are the paths to the market and } \\
\text { how relevant are digital trading methods } \\
\text { (e-commerce, m-commerce)? }\end{array}$ \\
\hline & $\begin{array}{l}\text { Where does most of the income and } \\
\text { profits come from? }\end{array}$ \\
\hline & $\begin{array}{l}\text { What are the main segments of the } \\
\text { client and should something change in } \\
\text { that regard? }\end{array}$ \\
\hline & $\begin{array}{l}\text { How is it different from the competition } \\
\text { and how relevant is it in the future? }\end{array}$ \\
\hline \multirow{3}{*}{$\begin{array}{l}\text { Structure (what is } \\
\text { the organizational } \\
\text { structure) }\end{array}$} & $\begin{array}{l}\text { What is the type of organizational } \\
\text { structure? }\end{array}$ \\
\hline & $\begin{array}{l}\text { What is the balance between local and } \\
\text { global decision making? }\end{array}$ \\
\hline & $\begin{array}{l}\text { Where are the different digital aspects } \\
\text { located in your organization, is it } \\
\text { effective? }\end{array}$ \\
\hline \multirow{3}{*}{$\begin{array}{l}\text { People } \\
\text { (Employees } \\
\text { working in the } \\
\text { organization) }\end{array}$} & $\begin{array}{l}\text { What is the digital awareness of } \\
\text { employees in different parts of the } \\
\text { organization? }\end{array}$ \\
\hline & $\begin{array}{l}\text { What is the digital awareness of } \\
\text { executives? }\end{array}$ \\
\hline & $\begin{array}{l}\text { What new skills are needed and how to } \\
\text { acquire them? }\end{array}$ \\
\hline \multirow{3}{*}{$\begin{array}{l}\text { Processes (how } \\
\text { activities are } \\
\text { performed) }\end{array}$} & $\begin{array}{l}\text { To what extent are processes } \\
\text { automated and digitized? }\end{array}$ \\
\hline & $\begin{array}{l}\text { To what extent are processes } \\
\text { consistent throughout the organization? }\end{array}$ \\
\hline & $\begin{array}{l}\text { To what extent do processes adapt to } \\
\text { change? }\end{array}$ \\
\hline \multirow{5}{*}{$\begin{array}{l}\text { IT Capacities } \\
\text { (how information } \\
\text { is managed) }\end{array}$} & $\begin{array}{l}\text { How efficient is the IT infrastructure } \\
\text { (core system, network, databases) and } \\
\text { can it support digital ambitions? }\end{array}$ \\
\hline & $\begin{array}{l}\text { How effective is the outward-facing part } \\
\text { of IT: websites, mobile sites, social } \\
\text { media? }\end{array}$ \\
\hline & $\begin{array}{l}\text { How effective is the customer } \\
\text { relationship management system? }\end{array}$ \\
\hline & $\begin{array}{l}\text { Is there a clear IT strategy associated } \\
\text { with your corporate strategy? }\end{array}$ \\
\hline & $\begin{array}{l}\text { Are all elements of the system } \\
\text { connected in such a way as to provide } \\
\text { the necessary data, is the value } \\
\text { extracted from the data? }\end{array}$ \\
\hline \multirow{2}{*}{$\begin{array}{l}\text { Offer (products } \\
\text { and services) }\end{array}$} & How much are the products digitized? \\
\hline & How digitized are the services? \\
\hline \multirow{3}{*}{$\begin{array}{l}\text { Engagement } \\
\text { model (what is } \\
\text { the relationship } \\
\text { with customers, } \\
\text { suppliers, etc. ) }\end{array}$} & $\begin{array}{l}\text { How strong and developed is the } \\
\text { relationship with clients? }\end{array}$ \\
\hline & $\begin{array}{l}\text { How many points of contact are there } \\
\text { with clients (web, mobile, mail, face to } \\
\text { face) and how are they managed? }\end{array}$ \\
\hline & How loyal are customers? \\
\hline
\end{tabular}

Source: Wade, 2015 


\section{Influence of digital technologies on ERP systems}

Schallmo \& Williams (2017) addressed the technical aspects of digital transformation content, identifying the characteristic technologies that enable digital transformation. All digital technologies are classified into four categories that make up the so-called Digital Radar: Digital Data, Automation, Digital Client Access, and Networking. Figure 1 presents all four categories with associated digital technologies and their applications.

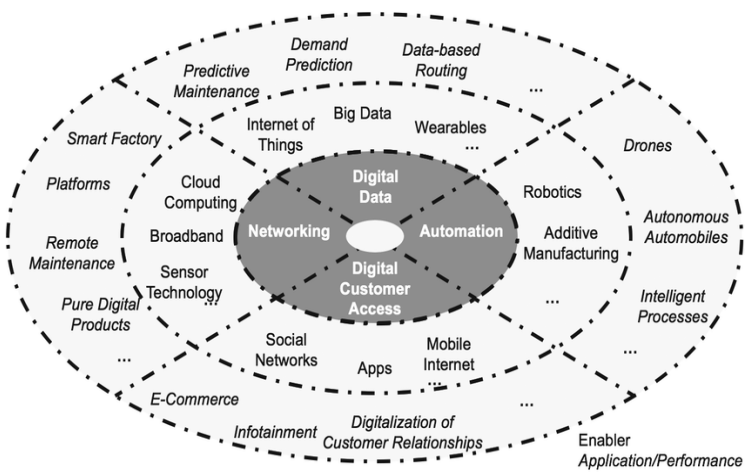

Figure 1 Digital radar with technologies and their applications

Source: Schallmo \& Williams, 2017

The most popular digital technologies of "Digital Radar" and their impact on ERP systems will be described in the following section of this chapter.

\subsection{Cloud technology and ERP systems}

Cloud technology is one of the most popular digital technologies. The key benefits are its availability and transparency, because its use is conditioned only by the connection to the Internet. Its biggest drawback, which is also the biggest obstacle for companies to use it to a greater extent, is data security. For this reason, there are several types of Cloud technology: Private Cloud (cloud is on a private network), Public Cloud (cloud is on the Internet), Hybrid Cloud (a combination of the previous two clouds) (Elbahri et al., 2019).

In previous decades, ERP systems have been available mainly to large companies to which investments in large software solutions would pay off. With the innovation of Cloud technology, ERP systems have become available to small companies as well (Nofal \& Yusof, 2013). Business via the cloud allows access to data from anywhere. It is possible to customize software packages to suit the needs of the company in the form of software modules that facilitate business.
The largest suppliers of cloud technology are Amazon.com, VMware, IBM, Salesforce.com, Google, Rackspace, Citrix Systems, IBM, etc. The largest suppliers of Cloud ERP systems are: Microsoft, SAP, Oracle, Intuit, Workday, Zero, etc. (Liyang, Zhiwei, Zhangjun, \& Li, 2011)

Using the Cloud ERP system has many advantages and challenges. Cloud systems provide real-time access to information and thus enable timely corporate decisions to be made (Liyang et al., 2011).

The way software works in the cloud affect the regulation of the entire business process and thus provides transparency and consistency of data throughout the system (Immhoff \& White, 2011). Cloud ERP systems are showing great popularity in the world, primarily because of their following characteristics:

1. Lower costs - the software solution is leased only for the required period of use, there is no purchase and storage of software on the company's server (Nofal \& Yusof, 2013)

2. Easy access to data - access to the software solution is possible from any location where there is an Internet connection (Ruíz, 2015)

3. Fast implementation - no purchase of servers and hiring of workers for infrastructure maintenance, with the help of Cloud technology only the server is rented from major suppliers (Immhoff \& White, 2011)

4. Business reorganization - eliminates unnecessary business processes so that the focus is on the main advantages of the company (Immhoff \& White, 2011)

5. Gaining strategic advantage - transparency of data throughout the business process enables faster decision-making focus on the main advantages of the company, and not on IT administration (Immhoff \& White, 2011)

The challenges that need to be addressed related to implementing the Cloud ERP system are:

- Data security (Liyang et al., 2011)

- Access control

- Lack of IT skills by users

- Limitations in integration with other software solutions (Immhoff \& White, 2011) 


\subsection{Internet of Things (IOT) and ERP systems}

IoT technologies perform communications between devices after which this data is transmitted to the company (manufacturer) via the Internet. IoT collects extensive databases that affect changes in the business process and its management using ERP systems. Because of a sizeable amount of data, companies cannot analyse them all because the analysis requires a lot of time and is expensive because of the small number of experts in this field.

An advantage of IoT is much greater and faster availability of data, which allows access to this data from any sector or place in the company. Real-time communication opens up the possibility for managers to get an overview of inventory reports, without depending on workers and their efficiency. If the company is engaged in the activity of courier services, it is then possible to follow, in real-time, the entire route of the shipment from sender to recipient with the help of IoT. Communication between physical devices is direct thus reducing data transmission costs (Elazhary, 2019).

IoT technology has its specific shortcomings, such as a connection to infrastructure, data security, and human resources. Should there be business interruptions or plant failures, this would cause huge losses (Elazhary, 2019). Because this technology is made up of the interconnection of multiple smart devices, data security is perilous (Dornean \& Rusu, 2019). One of the chief reason's companies do not use this technology to a greater extent is data security. Also, one disadvantage is less employment of people because the data is sent between devices with no human intervention. The way the business model works could cause changes in the number of employees in the company, which can be a potential problem. The conclusion is that the data got from the IoT will be the basis for a new generation of business systems that will change the way data is collected, processed, and analyzed that is currently used in ERP systems.

\subsection{Artificial intelligence (AI) and ERP systems}

AI learns algorithms that try to embed artificial intelligence in software that will perform certain types of tasks (Paschek, Luminosu \& Draghici, 2017). If we follow the development of digital technologies, it could be stated that there is a lot of progress on artificial intelligence. How advanced this technology is is stated by the fact that the robot Sofia (robot with AI) is recognized as a citizen of Saudi Arabia (Paschek et al., 2017). "Chatbots" (digital assistants) are available on most Internet sites to answer common questions from customers / interested parties. Companies, with the help of AI can influence business management using ERP systems by creating a learning algorithm that determines, based on historical data, what should be produced and what are the right amounts of inventories to produce based on entered historical data (Paschek et al., 2017).

If ERP systems use AI, then based on huge amounts of data, which are of different types, reports can be created, which may lead to less waste of resources or reduced costs, and eliminate unnecessary connections in the business process/model, etc. (Paschek et al., 2017).

With the help of AI, the largest companies in the world manage their plants that are geographically dislocated. It is possible to manage the entire production process, from production to sales. Procurement companies can track enormous quantities of goods. Tracking the movement of goods is facilitated because real-time analysis of turnover, consumer habits and enables the creation of offers of goods and services that correspond to consumer preferences (Kaplan \& Haenlein, 2019).

The disadvantages that accompany this technology stem from the fact that $\mathrm{AI}$ are robots/machines that perform a certain work and are limited only to certain tasks. Implementing this technology in companies is expensive, which also limits its application in companies (Kaplan \& Haenlein, 2019).

\subsection{Big data and ERP systems}

Big data is an extensive database that collects data from various sources, and their analysis is done by many scientists and experts (Comput et al., 2015).

The company must analyze each layer of data to get the right information. It is first necessary to group an enormous amount of data, which are from unique sources and original formats, then to filter this data, "clean" and finally analyze. Companies must strive to come up with the results of the analysis first to become competitive in the market and have an advantage over other companies that do not use this digital technology (Khan et al., 2014).

The main reason this digital technology is used is to make quick decisions based on the collected data, because in that way higher productivity can be achieved, costs are reduced (missed decisions), and transparency of all data on assets and processes is available, etc. (Comput et al., 2014). If the data got from the ERP system is well analyzed by experts, then companies with the help of Big data 
can find out a large amount of information about what customers want and thus adjust their offer (similar to IoT). ERP systems serve digital data. Big Data as another resource from which data to be analyzed is extracted, since ERP systems have a platform that is not suitable for analyzing sizeable amounts of data.

One disadvantage of this technology is that it is financially inaccessible. Experts who deal with analysis and mining in databases are expensive and their research can take a long time. For this reason, many companies do not have the financial capacity to keep huge amounts of data, nor do they have the tools to process/analyze that data. The biggest challenge for digital data big data is to reduce the cost and time required to get concrete results from the extensive databases that are created daily.

The technology that can help Big data overcome shortcomings is Cloud technology that overcomes problems by providing only that data that the company needs and the costs are proportional to the services provided. Accessing new data is much faster and simpler, no longer requiring a large infrastructure in the company to analyze the database.

\section{Results of empirical research}

Companies from several industries took part in the research. The largest share in the survey, as much as $32 \%$, were respondents from real estate management companies. Companies from trade, construction, and transport have approximately the same percentage share in the research, which is $16 \%$. Respondents who had a share of less than $10 \%$ in the survey come from companies belonging to the activities of catering, manufacturing, computer programming, and engineering.

Respondents who agreed to take part in the research belong to different job positions in companies. The largest percentage share is made up of employees with $72 \%$, followed by managers with $16 \%$, and last place are directors who make up $12 \%$ of respondents.

The first research goal was to determine how many small companies in Serbia use ERP systems and on which platforms. After collecting answers through a survey method and their analysis, it was found that the use of ERP systems is present in small companies but that there are diverse structures in terms of technology. Of the total number of companies surveyed, $68 \%$ use a traditional ERP system. The second place is occupied by the Cloud ERP system used by the surveyed companies, while the last place is occupied by the ERP Hybrid with $8 \%$ representation. Respondents who responded to using the ERP Hybrid argued that it was a transition period until they fully implemented Cloud technology. Given these statistics, it is expected that companies using the ERP Hybrid will implement Cloud technology shortly, which will increase the percentage of use of the Cloud ERP system from $24 \%$ to $32 \%$.

The results of the research show that the percentage of traditional ERP systems in small companies in Serbia is much higher than the percentage of Cloud ERP systems. However, the results of the research also show that over $50 \%$ of the surveyed companies want to switch to Cloud technology. Only $32 \%$ are companies that for various reasons do not yet intend to leave the traditional ERP system they already use.

Although the second research goal of the paper was to identify the major drivers and barriers to the use of Cloud ERP systems, they are systematized and described below based on the answers of the respondents.

\section{Driver to move to the Cloud}

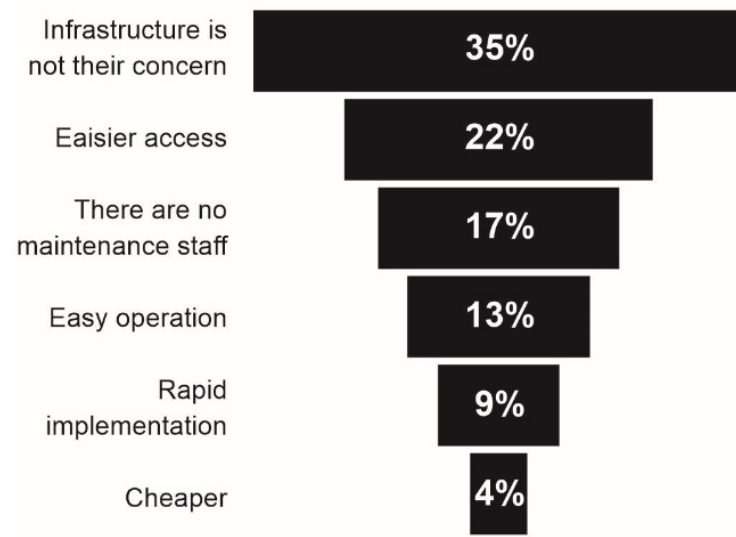

Figure 2: Drivers to move to the Cloud Source: the authors

The results of the research show that most respondents, in the amount of 35\%, confirmed that they want to switch to the Cloud ERP system because then the infrastructure "is not their concern", which makes this reason the first key advantage. Respondents know that with the transition to Cloud technology, the responsibility of maintenance shifts from the company to another person.

Another key advantage is easier access to the system. Of the $100 \%$ of respondents, $22 \%$ confirmed that they know how wide the availability of the ERP system is if it is based on Cloud technology. 
The third key advantage confirmed by $17 \%$ of respondents is the opinion that Cloud technology does not require employees to maintain the system. Respondents who state that this is an advantage of Cloud technology are mostly private companies that have only one person to maintain the software.

The fourth key advantage is the very easy management of the company's business. This reason for switching to the Cloud ERP system is seen by only $13 \%$ of companies as an advantage.

The fifth key advantage is the faster implementation of the Cloud ERP system, 9\% of respondents confirmed. Respondents believe that implementing the Cloud ERP system takes less time than the traditional situation. They explain their answers by saying that the software on the Cloud is immediately ready for use.

The last key advantage that the respondents mentioned is that they think the Cloud ERP system is cheaper than the traditional ERP system. The number of respondents who made this statement is at a tiny percentage level of $4 \%$.

\section{Barriers to move to the Cloud}

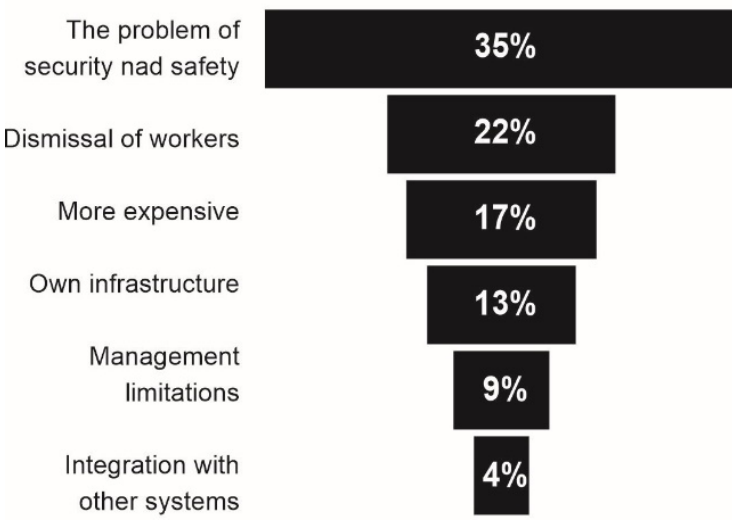

Figure 3: Barrier to move to the Cloud Source: the authors

The results of the research show that $40 \%$ of respondents agree that the major barrier to implementing the Cloud ERP system is the problem of data security and safety. Respondents feel that important business data is not as secure as on their infrastructure.

Another key barrier is the dismissal of workers, which is the major reason for not using the Cloud ERP system mainly in public companies, which make up $20 \%$ of our respondents. Respondents state that layoffs would produce additional enormous costs for severance pay, because an entire sector has employees engaged in infrastructure maintenance.
The third key barrier to transition to Cloud technology is the belief of $16 \%$ of respondents that implementing the ERP Cloud system is more expensive than traditional ERP. Based on a review of the professional literature, the author Salleh points out the following advantages of Cloud ERP systems: reduction of hardware and licensing costs, lower operating costs, reduced upgrade costs, easier implementation, and the ability to transfer internal resources to other tasks and focus on the company's core business function (Salleh, Teoh, \& Chan 2012).

The fourth key barrier is the existence of its infrastructure. Respondents who explained that switching to Cloud technology would be at an enormous loss because of previous enormous investments in infrastructure make up $12 \%$ of companies.

The fifth key barrier is the management constraint mentioned by $8 \%$ of respondents in their responses. This reason is explained by the fact that the Cloud ERP system is not sufficiently adapted to the current business model of the company and its current functioning. With traditional ERP systems, they believe that there are many more adjustments, but that is why their implementation takes longer.

The last barrier, accounting for the lowest percentage in the amount of $4 \%$ of the above answers, is integration with other systems. Respondents think that other systems are very difficult to integrate with the Cloud ERP system. In their answers, they explain that these systems do not provide enough possibilities to adapt to other systems, unlike the traditional ERP system.

\section{Conclusion}

Digital business transformation implies changes in the established way of doing business, due to the application of modern digital technologies, to achieve greater performance and achievements of companies. The authors describe the most popular digital technologies and their impact on the development of modern ERP systems.

The results of the conducted empirical research lead to the conclusion that the percentage of modern ERP systems in small companies in Serbia is lower than the representation of traditional ERP systems. Specifically, only $24 \%$ of small companies that took part in the survey use the Cloud ERP system. Traditional ERP systems are represented in $68 \%$ of surveyed companies. This seemingly illogical decision of small companies to use traditional ERP systems to a greater extent is 
supported because almost half of these companies, do not intend to leave the traditional ERP system they use, because of the existing infrastructure and business data security concerns. The other half of the companies are in the process of transition from the traditional to the Cloud ERP system, which will soon affect the change in the current picture of the representation of modern ERP systems in small companies.

The results of empirical research show that many companies have some conflicting opinions about the barriers and benefits of Cloud ERP systems. Specifically, the research results show that price occupies $16 \%$ in the structure of all identified barriers and is the third reason companies have resistance to Cloud ERP systems. On the identified list of drivers for implementing Cloud ERP, the price was also found as a factor, but in this case negligible with only $4 \%$ in the structure of all drivers. The research results in terms of price are not in agreement with the findings in the literature. Namely, Cloud ERP systems are more favorable than traditional ERP systems because of the lack of infrastructure costs and its maintenance, payment by the use of resources, and the absence of additional memory costs (Picek et al., 2017).

We can conclude that small companies in Serbia need adequate education in terms of the advantages that modern ERP systems provide them compared to traditional ERP systems. Modern digital technologies will have an even greater impact on the advancement and capabilities of modern ERP systems, so small companies must understand the importance of their application.sm

\section{References}

Comput, J. P. D., Assunção, M. D., Calheiros, R. N., Bianchi, S., Netto, M. A. S., \& Buyya, R. (2015). Big Data computing and clouds: Trends and future directions. J. Parallel Distrib. Comput., 79-80, 3-15. https://doi.org/10.1016/j.jpdc.2014.08.003

Dornean, A., \& Rusu, V. D. (2019). a Case Study on Csr Practices in Romania in the Context of Eu Legislation. In European Union Financial Regulation and Administrative Area (Eufire 2019).

Elazhary, H. (2019). Journal of Network and Computer Applications Internet of Things ( IoT ), mobile cloud, cloudlet, mobile loT, loT cloud, fog , mobile edge , and edge emerging computing paradigms: Disambiguation and research directions. Journal of Network and Computer Applications, 128(October 2018), 105-140. https://doi.org/10.1016/j.jnca.2018.10.021
Elbahri, F. M., Al-sanjary, O. I., Ali, M. A. M., Naif, Z. A., Ahmed, O., \& Mohammed, M. N. (2019). Difference Comparison of SAP, Oracle, and Microsoft Solutions Based on Cloud ERP Systems : A Review. 2019 IEEE 15th International Colloquium on Signal Processing \& Its Applications (CSPA), March, 65-70. https://doi.org/10.1109/CSPA.2019.8695976

Hess, T., Benlian, A., Matt, C., \& Wiesböck, F. (2016). Options for Formulating a Digital Transformation Strategy. MIS Quarterly Executiv, 2016(June), 17-33.

Immhoff, C., \& White, C. (2011). Self-Service Business Intelligence: Empowering Users to Generate Insights. TDWI Report, 1-37.

Kaplan, A., \& Haenlein, M. (2019). Siri , Siri , in my hand: Who 's the fairest in the land? On the interpretations, illustrations, and implications of arti fi cial intelligence. Business Horizons, 62(1), 15-25. https://doi.org/10.1016/j.bushor.2018.08.004

Khan, N., Yaqoob, I., Abaker, I., Hashem, T., Inayat, Z., Kamaleldin, W., Ali, M., Alam, M., Shiraz, M., \& Gani, A. (2014). Big Data: Survey, Technologies , Opportunities, and Challenges. 2014. https://doi.org/10.1155/2014/712826

Leipzig, T. Von, Gamp, M., Manz, D., \& Schöttle, K. (2017). Initialising customer-orientated digital transformation in enterprises. Procedia Manufacturing, 8(October 2016), 517-524. https://doi.org/10.1016/j.promfg.2017.02.066

Liyang, T., Zhiwei, N., Zhangjun, W., \& Li, W. (2011). A conceptual framework for business intelligence as a service (SaaS BI). Proceedings - 4th International Conference on Intelligent Computation Technology and Automation, ICICTA 2011, 2, 1025-1028. https://doi.org/10.1109/ICICTA.2011.541

Matt, C., Hess, T., \& Benlian, A. (2015). Digital Transformation Strategies. Business and Information Systems Engineering, 57(5), 339-343. https://doi.org/10.1007/s12599-015-0401-5

Nofal, M. I., \& Yusof, Z. M. (2013). Integration of Business Intelligence and Enterprise Resource Planning within Organizations. Procedia Technology, 11(December 2013), 658-665. https://doi.org/10.1016/j.protcy.2013.12.242

Paschek, D., Luminosu, C. T., \& Draghici, A. (2017). Automated business process management - in times of digital transformation using machine learning or artificial intelligence. MATEC Web of Conferences, 121. https://doi.org/10.1051/matecconf/201712104007

Polit, D. F., \& Beck, C. T. (2006). The Content Validity Index: Are You Sure You Know What's Being Reported? Critique and Recommendations. Research in Nursing \& Health, 29, 489-497. https://doi.org/10.1002/nur.20147

Picek, R., Mijac, M., \& Androcec D. (2017). Acceptance of Cloud ERP systems in Croatian companies: Analysis of key drivers and barriers. Economic and Social Development 20, April, 27-28.

Ruiz, A. A. B. (2015). Combining business intelligence with cloud computing to delivery agility in actual economy. Information Systems - Business Informatics, (January 2011), 54-67. 
Salleh, S. M., Teoh, S. Y., \& Chan, C. (2012). Cloud enterprise systems: A review of literature and its adoption. Proceedings - Pacific Asia Conference on Information Systems, PACIS 2012.

Schallmo, D., \& Williams, C. (2017). Digital transformation of business models - best practice, enablers, and roadmap. International Journal of Innovation Management, 21(8), 1-17.

https://doi.org/10.1142/S136391961740014X

\section{$\triangle$ Correspondence}

\section{Mirjana Marić}

University of Novi Sad, Faculty of Economics in Subotica

Segedinski put, 24000, Subotica, Serbia

E-mail: mirjana.maric@ef.uns.ac.rs
Wade, M. (2015). Digital business transformation. Global Center for Digital Business Transformation, (June), 1-9. 